\title{
A Web-based Alternative Non-animal Method Database for Safety Cosmetic Evaluations
}

\author{
Seung Won Kim and Bae-Hwan Kim \\ Major in Public Health, Faculty of Food and Health Sciences, Keimyung University, Daegu, Korea
}

(Received March 15, 2016; Revised April 5, 2016; Accepted April 11, 2016)

\begin{abstract}
Animal testing was used traditionally in the cosmetics industry to confirm product safety, but has begun to be banned; alternative methods to replace animal experiments are either in development, or are being validated, worldwide. Research data related to test substances are critical for developing novel alternative tests. Moreover, safety information on cosmetic materials has neither been collected in a database nor shared among researchers. Therefore, it is imperative to build and share a database of safety information on toxicological mechanisms and pathways collected through in vivo, in vitro, and in silico methods. We developed the CAMSEC database (named after the research team; the Consortium of Alternative Methods for Safety Evaluation of Cosmetics) to fulfill this purpose. On the same website, our aim is to provide updates on current alternative research methods in Korea. The database will not be used directly to conduct safety evaluations, but researchers or regulatory individuals can use it to facilitate their work in formulating safety evaluations for cosmetic materials. We hope this database will help establish new alternative research methods to conduct efficient safety evaluations of cosmetic materials.
\end{abstract}

Key words: Database, Alternative method, Animal test, Cosmetic testing

\section{INTRODUCTION}

It is undeniable that animal research has significantly contributed to evaluating the safety and efficacy of chemicals (1). However, animal testing has recently come under criticism from consumers and animal rights groups. Therefore, novel validated alternatives to animal testing must be established following the 3R approach (replacement, reduction, and refinement) and should be regulated and registered (2). Bans on acute and repeated-dose animal tests are currently being enforced in many industries, including cosmetics, and alternative methods are of interest to researchers in Korea and worldwide $(3,4)$. Many in vitro and in silico methods have been suggested to replace existing in vivo animal tests (2). Some examples of alternative methods of cosmetics testing include the human corneal epithelium model for eye irritation and the reconstructed human

Correspondence to: Bae-Hwan Kim, Major in Public Health, Faculty of Food and Health Sciences, Keimyung University, 1095 Dalgubeoldaero, Dalseo-gu, Daegu 42601, Korea

E-mail: kim9399@kmu.ac.kr

This is an Open-Access article distributed under the terms of the Creative Commons Attribution Non-Commercial License (http:// creativecommons.org/licenses/by-nc/3.0) which permits unrestricted non-commercial use, distribution, and reproduction in any medium, provided the original work is properly cited. epidermis test for skin irritation (5).

Proposed alternative methods must be validated according to rigorous validation procedures (6). Validating alternative methods that are highly correlated with animal tests is difficult. Furthermore, it is necessary to include various compounds as positive and negative controls to validate an in vitro test with the purpose of replacing an in vivo test (7) and the results from in vivo animal tests are required for use as references. In addition, information on the physical and chemical properties of compounds is essential to effectively use in silico tools. As such, large amounts of data must be stored, saved, and retrieved safely and efficiently after being consolidated in a database.

The European Union Reference Laboratory for alternatives to animal testing (EURL-ECVAM) is an institute specialized in validating alternative methods to animal testing. EURL-ECVAM accumulated data and provided the public ECVAM Database Service on Alternative Methods to Animal Experimentation (DB-ALM) (8). This service provides information relevant to the development and application of alternative techniques, including methodology, project type, compound and test results, authors and institutions, and references. It is not limited to cosmetic testing, but can also be used for biomedical sciences and toxicology research and regulations.

Since compounds used or tested in modern cosmetics are 
either relatively safe or less irritating than the alternatives (9), cosmetic testing has been included in the first group of industries in which animal tests are being banned. Cosmetics are important export products in South Korea and Korean cosmetic brands are gaining prominence in the global market (10). The Consortium of Alternative Methods for Safety Evaluations of Cosmetics (CAMSEC) was a research group working toward developing and validating alternative methods for cosmetics safety evaluations; the group was funded by the Korean Ministry of Food and Drug Safety (KMFDS).

We have built a database of alternative methods for cosmetics safety evaluations, the integrated CAMSEC database, available at http://camsec.kr/. The EURL-EVACM and CAMSEC databases share the same goal of promoting the development and dissemination of alternative methods and approaches; furthermore, the databases are both applicable to industry and accepted by regulators. Compared to the EURL-EVCAM database, the CAMSEC database is more tailored to cosmetic safety testing and provides more information, including animal test data. Comiskey et al. (11) developed a similar novel database focusing on exposure to fragrance ingredients in cosmetics and personal care products.

The objective of CAMSEC database was to provide systemic information on (a) test compounds, (b) the safety evaluation results of compounds from animal and alternative tests, (c) the mechanisms, methodologies, and reliability of available alternative methods, and (d) integrated testing strategies in the form of a web-based database to facilitate research on alternative methods and their validation processes.

\section{MATERIALS AND METHODS}

We used Linux CentOS as the operating system and Structured Query Language (MySQL) as the database management system. The system runs online and Hypertext Preprocessor (PHP) and JavaScript are used as the web programming languages. The major principle guiding the system is maintenance of free and open access to data such that the entire contents of the CAMSEC database are accessible to registered users.

The first step of building the CAMSEC database started with defining the database structures and the inter-database relationships. A brief entity-relationship diagram of the CAMSEC database is presented in Fig. 1. The diagram explains two different aspects of database access: users and system administrator. Users can search the database and use the results. If users cannot find the desired chemical information, they can submit 'new test substance forms' and request an update. Four forms are available via which to request chemical information, alternative methods information, animal toxicology information, and chemical efficacy information. While data can be gathered and submitted by any registered user via these forms, new data can only be registered by a group of regulators designated by the CAMSEC research team (to ensure its reliability).

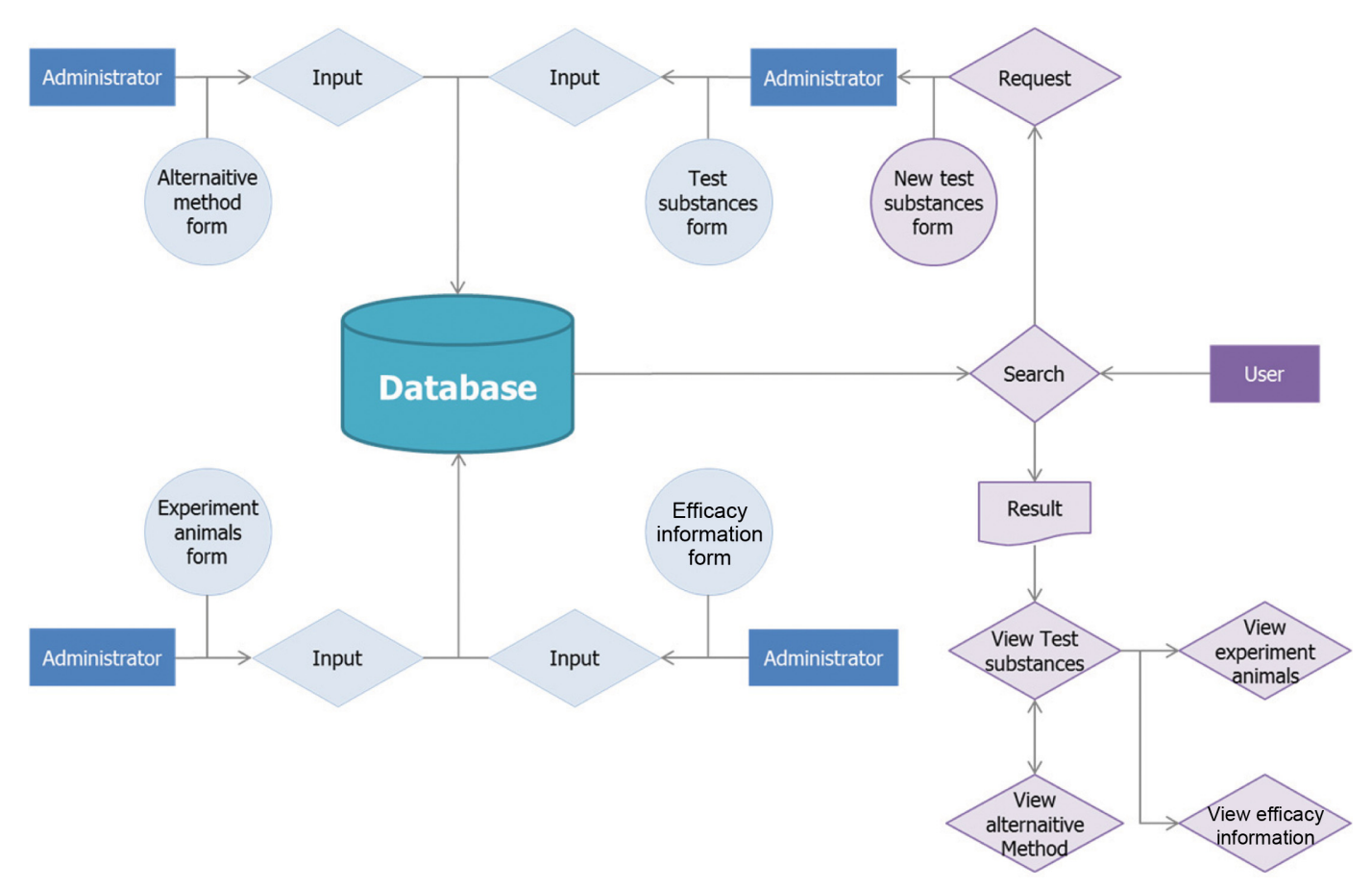

Fig. 1. The E-R (Entity-Relationship) diagram of CAMSEC database. 
Table 1. Source of collected data

\begin{tabular}{|c|c|c|}
\hline Category & Institute & Web address \\
\hline $\begin{array}{l}\text { Validation Authorities of } \\
\text { Alternative Methods }\end{array}$ & $\begin{array}{l}\text { ECVAM (EU) } \\
\text { ICCVAM (USA) } \\
\text { ZEBET (Germany) } \\
\text { JaCVAM (Japan) } \\
\text { NKCA (Netherland) } \\
\text { NC3Rs (UK) } \\
\text { ICATM (International) }\end{array}$ & $\begin{array}{l}\text { ecvam.jrc.it } \\
\text { iccvam.niehs.nih.gov } \\
\text { www.bfr.bund.de/en/zebet-58194.html } \\
\text { jacvam.jp } \\
\text { www.nkca.nl } \\
\text { www.nc3rs.org.uk } \\
\text { iccvam.niehs.nih.gov/about/icatm.htm }\end{array}$ \\
\hline $\begin{array}{l}\text { Research Institutes of } \\
\text { Alternative Methods }\end{array}$ & $\begin{array}{l}\text { ECOPA (EU) } \\
\text { 3R Research Foundation (Swiss) } \\
\text { Norecopa (Norway) } \\
\text { CARDAM (Belgium) } \\
\text { IIVS (USA) }\end{array}$ & $\begin{array}{l}\text { www.ecopa.eu } \\
\text { www.forschung3r.ch/en/news/ index.html } \\
\text { www.norecopa.no } \\
\text { www.cardam.eu } \\
\text { www.iivs.org }\end{array}$ \\
\hline $\begin{array}{l}\text { Research Companies of } \\
\text { Alternative Researches }\end{array}$ & $\begin{array}{l}\text { Axiogenesis } \\
\text { CeeTox } \\
\text { Cellectis } \\
\text { Celsis } \\
\text { MB Research Labs } \\
\text { GE Healthcare } \\
\text { Cellular Dynamics } \\
\text { Epithelix Sarl } \\
\text { Johnson \& Johnson } \\
\text { Unilever }\end{array}$ & $\begin{array}{l}\text { www.axiogenesis.com } \\
\text { www.ceetox.com } \\
\text { www.cellartis.com } \\
\text { www.invitrotech.com } \\
\text { www.mbresearch.com } \\
\text { www.gelifesciences.com } \\
\text { www.cellulardynamics.com } \\
\text { www.epithelix.com } \\
\text { www.jnj.com } \\
\text { www.unilever.com }\end{array}$ \\
\hline $\begin{array}{l}\text { Research Consortium of } \\
\text { Alternative Methods }\end{array}$ & $\begin{array}{l}\text { EPAA } \\
\text { Human Toxicology Project Consortium }\end{array}$ & $\begin{array}{l}\text { ec.europa.eu/enterprise/epaa/index_en.htm } \\
\text { htpconsortium.org }\end{array}$ \\
\hline International Society & $\begin{array}{l}\text { WCAA } \\
\text { EUSAAT } \\
\text { JSAAE } \\
\text { SOT }\end{array}$ & $\begin{array}{l}\text { www.eusaat.org } \\
\text { www.asas.or.jp/jsaae/e_aboutjsaae.html } \\
\text { www.toxicology.org }\end{array}$ \\
\hline $\begin{array}{l}\text { Infra of Alternative } \\
\text { Methods }\end{array}$ & $\begin{array}{l}\text { CAAT } \\
\text { Altweb } \\
\text { AltTox } \\
\text { FRAME } \\
\text { UC Davis Center for Animal Alternatives } \\
\text { EURCA } \\
\text { InterNICHE }\end{array}$ & $\begin{array}{l}\text { caat.jhsph.edu } \\
\text { altweb.jhsph.edu } \\
\text { alttox.org } \\
\text { www.frame.org.uk } \\
\text { www.lib.ucdavis.edu/dept/animalalternatives } \\
\text { www.eurca.org } \\
\text { www.interniche.org/en }\end{array}$ \\
\hline
\end{tabular}

Next step was to fill the database with various information. Information on alternative methods was collected from various institutions, including validation authorities and commercial product providers (Table 1). However, the data were collected solely from scientific references and are not the property of the CAMSEC research team.

\section{RESULTS}

The development of the database system was completed at the end of 2015 and its ownership was transferred to KMFDS. KMFDS started the second campaign to develop alternative methods in 2016 and will continue to update the CAMSEC database. At the end of 2015, the CAMSEC database provided information on 396 substances, 18 alternative methods, 7 animal test methods, and 38 functional categories.

The content of the CAMSEC database can be classified into four categories: chemical information (Table 2), alternative methods information (Table 3), animal toxicology information, and chemical efficacy information (Table 4). This information is available in English and Korean at http:// camsec.kr/dbsearch/page1.htm. In the left column of the webpage, there are five sub-menus: Chemical Info, Alternative Method Info, Animal Tox Info, Chemical Efficacy Info, and QSAR Search (Fig. 2). Moreover, information is listed in alphabetical order and is available in Korean and English.

Chemical information is available under Substance Information and includes information on chemical indexing, chemical efficacy, animal toxicity, alternative methods, and physicochemical characteristics (Fig. 3). Using chemical names is a poor indexing method of chemical compounds, 
Table 2. Establishment of chemical information

\begin{tabular}{ll}
\hline \hline Information category & Contents \\
\hline Chemical Identity & CAS No., EINECS No., Chemical Name (Korean, English), Synonymous Name, and their References \\
Chemical Efficacy Information & Categories and its Subclasses \\
Chemical Toxicity Information & Animal Toxicity Results, Alternative toxicity Results \\
Chemical Physical Condition & Color, Odor, Molecular weight, Molecular formula (Normal), Molecular formula (SMILES), Boiling \\
& Point, Freezing Point, Melting point, Vapor density, Vapor density measured temperature, Specific \\
& gravity (water-1), Specific gravity measured temperature, Solubility, pH, Volatile, Odor threshold, \\
& Evaporation rate, Viscosity,Viscosity measured temperature, Octanol-water partition coefficient, Solu- \\
& bility, Chemical structure, Other information, and their References \\
\hline
\end{tabular}

Table 3. Establishment of alternative method information

\begin{tabular}{|c|c|}
\hline Areas & Alternative methods to animal tests \\
\hline Single Dose Toxicity & $\begin{array}{l}\text { - Fixed Dose Procedure for Acute Oral Toxicity Testing (OECD guideline 420; Dec 2001) } \\
\text { - Acute Toxic Class Method for Acute Oral Toxicity Testing (OECD guideline No. 423; Dec 2001) } \\
\text { - Up-and-Down Procedure for Acute Oral Toxicity Testing (OECD guideline 425; Dec 2001) }\end{array}$ \\
\hline Eye Irritation & $\begin{array}{l}\text { - The Bovine Corneal Opacity and Permeability (BCOP) Test Method for Identifying Ocular Corrosives and } \\
\text { Severe Irritants (OECD guideline 437; Sep 2009) } \\
\text { - Isolated Chicken Eye (ICE) Test Method for Identifying Ocular Corrosives and Severe Irritants (OECD } \\
\text { guideline 438; Sep 2009) } \\
\text { - The Porcine Corneal Opacity and Permeability (PCOP) Test Method } \\
\text { - Human Corneal Epithelim (HCE) Model - MatTek EpiOcular, Labcyte Cornea Model, MCTT HCE Model } \\
\text { etc. } \\
\text { - Hen's Egg Test-Chorioallantoic Membrane (HET-CAM) Assay } \\
\text { - Fluorescein leakage (FL) method (OECD guideline 460; Oct 2012) }\end{array}$ \\
\hline $\begin{array}{l}\text { Skin Corrosion } \\
\text { and Irritation }\end{array}$ & $\begin{array}{l}\text { - In Vitro Skin Corrosion: Rat Transcutaneous Electrical Resistance Test (TER) (OECD guideline 430; Apr } \\
\text { 2004) } \\
\text { - In Vitro Skin Corrosion: Human Skin Model Test) (OECD guideline 431; Apr 2004) } \\
\text { - In Vitro Skin Corrosion: Human Skin Model Test - SkinEthic EpiSkin }{ }^{\mathrm{TM}} \text {, MatTek EpiDerm }{ }^{\mathrm{TM}} \text { (OECD guide- } \\
\text { line 431; Apr 2004) } \\
\text { - In Vitro Membrane Barrier Test Method for Skin Corrosion (OECD guideline 435; July 2006) } \\
\text { - In Vitro Skin Irritation: Reconstructed Human Epidermis Test Method - SkinEthic EpiSkin }{ }^{\mathrm{TM}} \text {, MatTek Epi- } \\
\text { Derm }^{\mathrm{TM}}, \text { MCTT KeraSkin }{ }^{\mathrm{TM}}-\text { VM Model (OECD guideline 439; July 2010) }\end{array}$ \\
\hline Skin Sensitization & $\begin{array}{l}\text { - Skin Sensitization: Local Lymph Node Assay (LLNA) (OECD guideline 429; Apr 2002) } \\
\text { - Skin Sensitization: Local Lymph Node Assay (LLNA): BrdU - ELISA (OECD guideline 442B; July 2010) } \\
\text { - Skin Sensitization: Local Lymph Node Assay (LLNA): BrdU - FCM } \\
\text { - Skin Sensitization: Local Lymph Node Assay (LLNA): DA (OECD guideline 442A; July 2010) } \\
\text { - Skin Sensitization: Keratinocyte Model - HEL-30, HaCaT } \\
\text { - Skin Sensitization: RHE Model - MCTT } \\
\text { - KeraSkin }{ }^{\text {TM }} \text {-VM Model }\end{array}$ \\
\hline Phototoxicity & $\begin{array}{l}\text { - In Vitro 3T3 NRU Phototoxicity Test (OECD guideline 432; Apr 2004) } \\
\text { - Photohemolysis } \\
\text { - Reactive Oxygen Species (ROS) method }\end{array}$ \\
\hline Photosensitization & - Photosensitiztion: Keratinocyte Model - HaCaT \\
\hline Skin Absorption & - Skin Absorption: In Vitro Method (OECD guideline 428; Apr 2004) \\
\hline Oral Mucosal Irritation & - Reconstructed Human Oral Epithelium (HOE) Model - MatTek EpiOral ${ }^{\mathrm{TM}}$, SkinEthics HOE, MCTT HOE \\
\hline
\end{tabular}

so CAS numbers are used instead to provide a better primary indexing method for the database. Chemical mixtures have not been included; therefore, individual compounds are indexed separately. All toxicological information from animal tests and alternative methods in the CAMSEC data- base for a given chemical are retrieved and listed, and a link to each toxicological test is provided. Physicochemical characteristics are useful parameters for quantitative structure-activity relationship (QSAR) program data (12). In the QSAR Search sub-menu, a summary of the information 
Table 4. Establishment of chemical efficacy information

\begin{tabular}{ll}
\hline \hline Efficacy category & Sub-category \\
\hline Cosmeceuticals & Anti-wrinkle agents, Whitening agents, Sunblock agents \\
Oily materials & Oils and fats, wax esters, etc. \\
Surfactants & Anionic surfactants, Cationic surfactants, Amphoteric surfactants, Nonionic surfactants, etc. \\
Polymers & Thickening agents, Film formers, etc. \\
Antiseptic agents & Disinfectant, germicide, Antimicrobial agents, etc. \\
Ultraviolet absorbents & Benzophenone derivatives, p-Aminobenzoic acid derivatives, Salicylic acid derivatives, etc. \\
Others & Fragrance agents, Dye, Sequestering agents, Antioxidants, Humectants, and the Others \\
\hline
\end{tabular}

Alternatives DB
\begin{tabular}{|l|l|}
\hline Q & Alternatives DB \\
\hline ⿴囗口 & New substances registration \\
\hline 毘 & QSAR information \\
\hline
\end{tabular}

\begin{tabular}{|l|l|}
\multicolumn{2}{l}{ Alternatives DB } \\
\hline $\mathrm{Q}$ & Alternatives DB \\
\hline 回 & New substances registration \\
\hline 四 & QSAR information \\
\hline
\end{tabular}

\begin{tabular}{|l|l|} 
Alternatives DB \\
\hline Q & Alternatives DB \\
\hline 回 & New substances registration \\
\hline 围 & QSAR information \\
\hline
\end{tabular}

\begin{tabular}{|c|c|}
\hline \multicolumn{2}{|c|}{ Alternatives DB } \\
\hline$Q$ & Alternatives DB \\
\hline 目 & New substances re gistration \\
\hline 曲 & QSAR information \\
\hline
\end{tabular}
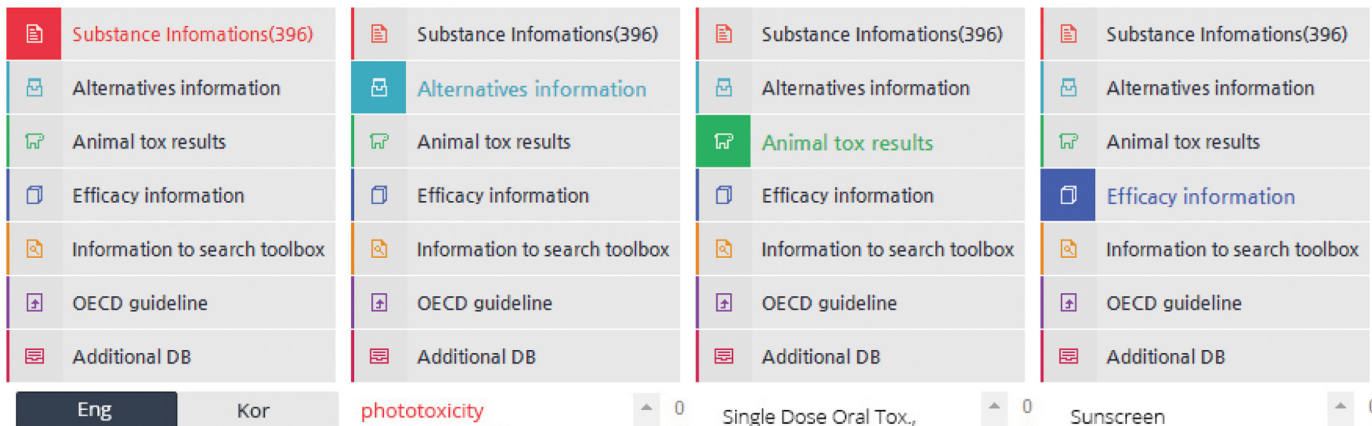

Eng Kor
1-Hexadecylpyridinium
bromide
1,2,3-Trichloropropane
1.2,4-Trimethylbenzene
1,2-Benzendiamine, 3-
methyl-, dihydrochloride
1,2-Benzenedicarboxylic
acid, bis(methylcyclohexyl)
ester
1,2-Propanediol
1,3-Benzenediamine, 4-
methoxy-5-methyl-
dihydrochloride
1,3-Decanedione, 1-
phenyl-
1,3-Diisopropylbenzene
1,3-Dioxane, 5-methyl-2-
(1-methylbutyl)-5-propyl-
1,3-Dioxolane, 4-((4--
methoxyphenoxy)methyl)-2
- methyl-

\begin{tabular}{ll}
\hline phototoxicity & 0 \\
- In Vitro 3T3 NRU assay & 1 \\
photosensitization & 2 \\
- Keratinocyte Model- HaCaT & 3 \\
\hline Oral Mucosal Irriitation & 4 \\
- HOE (Reconstructed Human & 5 \\
Oral Epithelium)- MatTek & 6 \\
EpiOralTM & 7 \\
- HOE - SkinEthics HOE & 8 \\
- HOE - MCTT HOE & 9 \\
\hline Eye Irritation & $\mathrm{A}$ \\
- HCE (Human Corneal & $\mathrm{B}$ \\
Epithelim) & $\mathrm{C}$ \\
- MatTek EpiOcular & $\mathrm{D}$ \\
- HCE (Human Corneal & $\mathrm{E}$ \\
Epithelim) & $\mathrm{F}$ \\
- Labcyte Cornea Model & $\mathrm{G}$ \\
- HCE (Human Corneal & $\mathrm{H}$ \\
Epithelim) & $\mathrm{I}$ \\
- MCT HCE Model & $\mathrm{J}$ \\
- BCOP (Bovine Corneal & $\mathrm{K}$ \\
Opacity and Permeability) & $\mathrm{L}$ \\
\hline
\end{tabular}

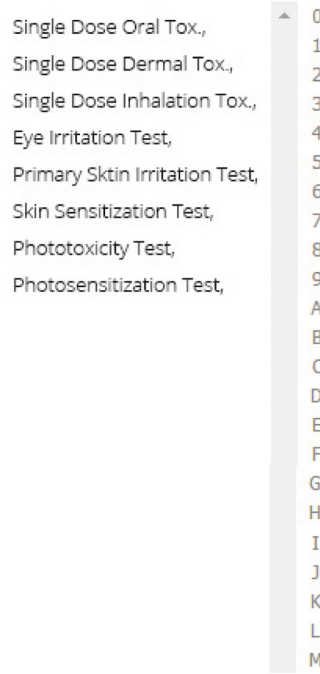

\begin{tabular}{|l|l|}
\hline Sunscreen & 0 \\
\hline Exfoliation & 1 \\
\hline Peeling agent & 2 \\
\hline Denaturing agent & 3 \\
Germicide & 4 \\
\hline Solvent & 5 \\
Emulsifying agent & 6 \\
\hline Antistatic Agents & 7 \\
\hline Synthetic resins & 8 \\
\hline Antiseptic, Antimicrobial & 9 \\
agent & $\mathrm{A}$ \\
\hline Dyeing agent & $\mathrm{B}$ \\
\hline Flavoring agent & $\mathrm{C}$ \\
& $\mathrm{D}$ \\
& $\mathrm{E}$ \\
& $\mathrm{F}$ \\
& $\mathrm{G}$ \\
& $\mathrm{H}$ \\
& $\mathrm{I}$ \\
& $\mathrm{J}$ \\
& $\mathrm{K}$ \\
& $\mathrm{L}$ \\
& $\mathrm{M}$ \\
\hline
\end{tabular}

Fig. 2. Snapshot of CAMSEC database for the data lists for each information category.

available on the indexed chemical is provided, including boiling point, freezing point, melting point, specific gravity, water solubility, viscosity, and water/octanol partition coefficient.

Alternative methods information (Fig. 4) and animal toxicological information have been classified into eight categories: single dose toxicity, eye irritation, skin corrosion and irritation, skin sensitization, phototoxicity, photosensitization, skin absorption, and oral mucosal irritation. These are the same categories that are used in conventional cosmetics safety tests based on animal experiments for which the CAMSEC database aims to develop non-animal methods. All methods have been developed and validated recently. Information on conventional animal toxicity tests is also provided so that the results of alternative methods can be compared to those of conventional animal toxicity tests. For each method, basic information is provided under the following sections: Background, Purpose, Toxicology 


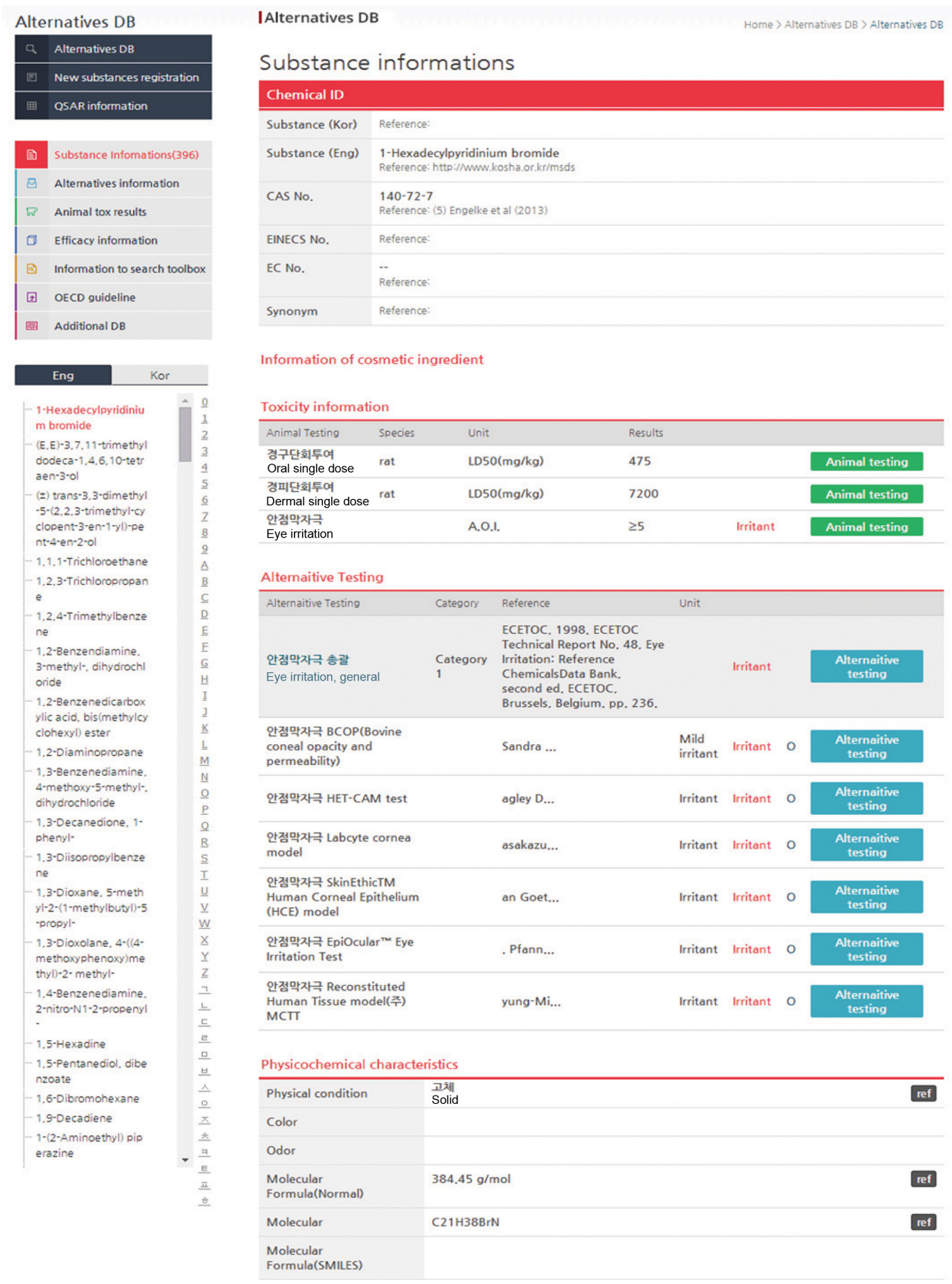

Fig. 3. Snapshot of CAMSEC database for chemical information.

mechanisms/Toxicology path, Test method, Test criteria, and References. For binary (positive or negative) results, reference chemicals are listed for the results of each validation process. Each chemical has a link that connects to its own chemical information page.

Chemical efficacy has been categorized into seven groups: cosmeceuticals, oily materials, surfactants, polymers, anti- septic agents, ultraviolet absorbents, and others (Table 4). This information has been further divided into 12 subcategories: sunscreen, exfoliation, peeling agent, denaturing agent, germicide, solvent, emulsifying agent, antistatic agent, synthetic resin, antiseptic/antimicrobial agent, dyeing agent, and flavoring agent. This information is unique and important to cosmetic testing. On the website, each group can be 


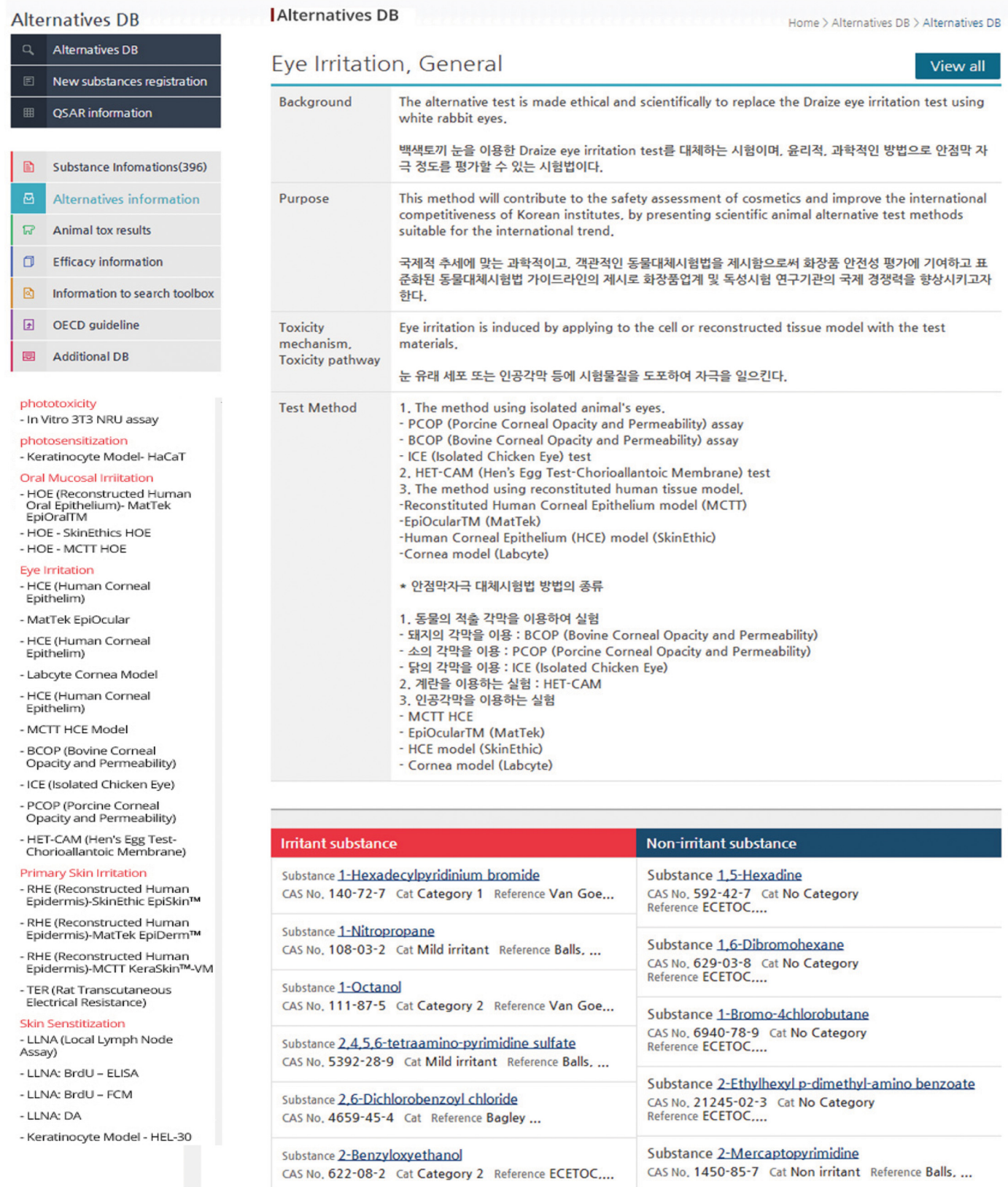

Fig. 4. Snapshot of CAMSEC database for alternative method information.

selected to display a list of chemicals with that property that have been tested and reported on in the literature.

The data sources have been categorized into five groups: validation authorities for alternative methods, research institutes employing alternative methods, research companies pursuing alternative research, international research consortiums using alternative methods, and infra of alternative methods (Table 1). As all alternative methods must be validated to be formally adopted by Korean and international regulatory authorities, validation authorities must have access to newly developed alternative methods and are expected to provide some guidelines on validation processes.

\section{DISCUSSION}

The CAMSEC research team consisted of three groups. Groups 1 and 2 developed new alternative methods, while Group 3 coordinated the validation processes, from the selection of test chemicals to inter-laboratory appraisal, and developed the database by collating all of the information that was provided to the other groups, and the information that the other groups created themselves during their studies. Each group worked closely from the early stages of alternative methods development to achieve data validation as soon as possible. Herein, we briefly describe those pro- 
cesses and how the CAMSEC database facilitated the development, validation, and collection of unique data. The actual products that underwent this process are exemplified by KeraSkin $^{\mathrm{TM}}$-VM, a novel, reconstructed human epidermis model for skin irritation tests (13) and LLNA:BrdU-FCM, a new non-radioisotopic local lymph node assay for skin sensitization tests (14). The process began with the development team working to provide a stable, alternative in vitro model for a certain test, such as a skin irritation test. Once complete, the validation group selected the test chemicals and provided them to the development group. Some established methods, such as OECD TG429, specify which chemical should be tested. The validation group entered the chemical information and animal test results into the database, which was used by the development group (who required access to any new information not already in the database). After completing intra- and inter-laboratory reproducibility tests, all results were archived in the CAMSEC database.

The CAMSEC database contains physical and chemical information on compounds tested for use in cosmetics. These data are an essential element of the structural information that informs QSAR tools, which represent an important branch of alternative methods and an important component of the integrated testing strategy (ITS). The CAMSEC database provides a link for each compound that connects users to this summarized information. In addition, the CAMSEC database homepage contains guides to several QSAR tools, including the OECD Toolbox and EPA TEST, in both written and video formats. This information is available at http:// camsec.kr/dbsearch/qsar.htm. The ITS requires use all types of information, from physicochemical characteristics to in vitro, in vitro, and in silico test results $(15,16)$. The CAMSEC database provides all the necessary information and will ultimately be able to inform ITS tools for eye irritation, skin corrosion and irritation, skin sensitization, and phototoxicity tests.

The CAMSEC database has been designed to share and exchange alternative methods data within the cosmetic testing community. Although this service focuses on cosmetics safety evaluations, most of the data can be applied to alternative methods in other areas. Another feature of the CAMSEC database is the integrated search function over all information categories, a feature that distinguishes it from other alternative method databases such as ECVAC DBALT. Eventually, user interactions and feedback are expected to improve the utility and functionality of the database.

The advantages of this endeavor are the specificity and practicality of the collected data. Data on cosmetics safety evaluations are systemically categorized based on test chemicals, method type (animal or alternative), toxicity information, and efficacy. By narrowing the scope of the CAMSEC database to cosmetics safety tests, we obtained and, as the first group, fully used, the data for our own studies. These strengths could also be considered limitations by researchers pursuing different goals. For now, it is expected that the main users of the CAMSEC website will be Korean researchers and, except for the database search engine, its contents are available only in Korean. Additional language support will be provided in the future.

\section{CONFLICT OF INTEREST}

The authors report no conflicts of interest. Only the authors are responsible for the content and writing of this article.

\section{ACKNOWLEDGEMENTS}

This study was supported by a grant (13172MFDS987) from the Korean Ministry of Food and Drug Safety.

\section{REFERENCES}

1. The Lancet (2004) Animal research is a source of human compassion, not shame. The Lancet, 364, 815-816.

2. Purchase, I.F. (1997) Prospects for reduction and replacement alternatives in regulatory toxicology. Toxicol. In Vitro, 11, 313-319.

3. Vinardell, M.P. and Mitjans, M. (2008) Alternative methods for eye and skin irritation tests: an overview. J. Pharm. Sci., 97, 46-59.

4. Barker, C. (2013) South Korea proposes to recognize animal testing alternatives [17-Dec-2013]. CosmeticsDesign-Asia.com. Available from: http://www.cosmeticsdesign-asia.com/Regulation-Safety/South-Korea-proposes-to-recognize-animal-testing-alternatives.

5. Jung, K.M., Lee, S.H., Ryu, Y.H., Jang, W.H., Jung, H.S., Han, J.H., Seok, S.H., Park, J.H., Son, Y., Park, Y.H. and Lim, K.M. (2011) A new 3D reconstituted human corneal epithelium model as an alternative method for the eye irritation test. Toxicol. In Vitro, 25, 403-410.

6. Zeiger, E. (2003) Validation and acceptance of new and revised tests: a flexible but transparent process. Toxicol. Lett., 140-141, 31-35.

7. Meyer, O. (2003) Testing and assessment strategies, including alternative and new approaches. Toxicol. Lett., 140-141, 2130 .

8. ECVAM (2015) EURL ECVAM Database service on Alternative Methods to animal experiment (DB-ALM). Available from: http://ecvam-dbalm.jrc.ec.europa.eu/beta.

9. McNamee, P., Hibatallah, J., Costabel-Farkas, M., Goebel, C., Araki, D., Dufour, E., Hewitt, N.J., Jones, P., Kirst, A., Le Varlet, B., Macfarlane, M., Marrec-Fairley, M., Rowland, J., Schellauf, F. and Scheel, J. (2009) A tiered approach to the use of alternatives to animal testing for the safety assessment of cosmetics: eye irritation. Regul. Toxicol. Pharmacol., 54, 197-209.

10. Whitehouse, L. (2014) More Korean cosmetics brands eyeing up China [26-Jun-2014]. CosmeticsDesign-Asia.com. Available from: http://www.cosmeticsdesign-asia.com/Business-Financial/ 
More-Korean-cosmetics-brands-eyeing-up-China.

11. Comiskey, D., Api, A.M., Barratt, C., Daly, E.J., Ellis, G., McNamara, C., O'Mahony, C., Robison, S.H., Safford, B., Smith, B. and Tozer, S. (2015) Novel database for exposure to fragrance ingredients in cosmetics and personal care products. Regul. Toxicol. Pharmacol., 72, 660-672.

12. Elena, L.P. and Andrew, W. (2010) Review of QSAR Models and Software Tools for predicting Developmental and Reproductive Toxicity (JRC59820). Publications Office of the European Union.

13. Jung, K.M., Lee, S.H., Jang, W.H., Jung, H.S., Heo, Y., Park, Y.H., Bae, S., Lim, K.M. and Seok, S.H. (2014) KeraSkin ${ }^{\mathrm{TM}}$ VM: A novel reconstructed human epidermis model for skin irritation tests. Toxicol. In Vitro, 28, 742-750.

14. Yang, H., Na, J., Jang, W.H., Jung, M.S., Jeon, J.Y., Heo, Y.,
Yeo, K.W., Jo, J.H., Lim, K.M. and Bae, S. (2015) Appraisal of within-and between-laboratory reproducibility of nonradioisotopic local lymph node assay using flow cytometry, LLNA: BrdU-FCM: Comparison of OECD TG429 performance standard and statistical evaluation. Toxicol. Lett., 234, 172-179.

15. De Wolf, W., Comber, M., Douben, P., Gimeno, S., Holt, M., Léonard, M., Lillicrap, A., Sijm, D., van Egmond, R., Weisbrod, A. and Whale, G. (2007) Animal use replacement, reduction, and refinement: Development of an integrated testing strategy for bioconcentration of chemicals in fish. Integr. Environ. Assess. Manag., 3, 3-17.

16. Jaworska, J. and Hoffmann, S. (2010) Integrated testing Strategy (ItS)-Opportunities to better use existing data and guide future testing in toxicology. ALTEX, 27, 231-242. 